\title{
Influence of fine recycled concrete aggregates on the properties of mortars
}

\author{
Zengfeng Zhao ${ }^{\mathrm{a}, \mathrm{b}, *}$, Sébastien Remond ${ }^{\mathrm{a}, \mathrm{b}}$, Denis Damidot ${ }^{\mathrm{a}, \mathrm{b}}$, Weiya $\mathrm{Xu}^{\mathrm{c}}$ \\ ${ }^{a}$ Université Lille Nord de France, Lille, France \\ ${ }^{\mathrm{b}}$ Civil and Environmental Engineering Department, Mines Douai, LGCgE GCE, Douai, France \\ ${ }^{\mathrm{c}}$ Geotechnical Research Institute, Hohai University, Nanjing, China
}

\section{H I G H L I G H T S}

- Influences of saturation state of FRCA on the mortars' properties are studied.

- Mortars made with dried FRCA present larger slump and better mechanical properties.

- Compressive strength of mortars decreases quasi linearly with substitution rate.

- Fraction 0/0.63 mm of FRCA has a worse effect on mechanical properties of mortars.

\section{A R T I C L E I N F O}

Article history:

Received 26 June 2014

Received in revised form 19 January 2015

Accepted 18 February 2015

\section{Keywords:}

Fine recycled concrete aggregates

Water absorption

Granular class

Mechanical property

Interfacial transition zone

\begin{abstract}
A B S T R A C T
Fine recycled concrete aggregates (FRCA) also called recycled sand, having particle sizes smaller than $5 \mathrm{~mm}$, are essentially composed of mortar and hardened cement paste. Therefore they induce a large water demand which makes them hard to recycle into mortar and concrete. In this paper, the properties of mortars containing FRCA have been studied, including fresh properties, mechanical properties and interfacial transition zone (ITZ) microstructure.

The influence of saturation state of FRCA (dried or saturated) on the properties of mortars of identical compositions has first been studied. The results showed that the slump of mortars containing dried FRCA is always larger than that of mortars containing saturated FRCA. Indeed, in the case of dried FRCA, the theoretical amount of absorbed water is added at the beginning of mixing leading to a temporary increase of the initial efficient $W / C$ ratio and volume of paste, leading to a better workability before its absorption into FRCA. On the contrary, the absorbed water in saturated FRCA is not readily available and thus cannot contribute to increase the initial efficient $W / C$ ratio. Moreover, the compressive strength of mortars containing dried FRCA is always larger than that of mortars made with saturated FRCA, which is attributed to a thinner interfacial transition zone improving its mechanical properties. The influence of the fraction of recycled sand and of the granular class of recycled sand on the mechanical properties of mortars has then been studied with saturated FRCA. The compressive strength of mortars decreases quasi linearly as the replacement percentage of recycled sand increases. Moreover, it is shown that the finer fraction of recycled sand $(0 / 0.63 \mathrm{~mm})$ has the worse effect on the mechanical properties of mortars.
\end{abstract}

(c) 2015 Elsevier Ltd. All rights reserved.

\section{Introduction}

Very large quantities of construction and demolition wastes are produced every year, nevertheless only a small fraction of them is recycled in the manufacture of concrete and mortar. A larger part of these materials could be recycled into concrete to decrease the amounts of wastes which have to be disposed in landfill, and thus to preserve natural resources [1-6].

* Corresponding author at: Civil and Environmental Engineering Department, Mines Douai, LGCgE GCE, Douai, France.
Old concrete is the most abundant material among various types of construction and demolition wastes. Recycled concrete aggregates (RCA) are composed of an intimate mix between aggregates and hardened cement paste [7-10]. The fine fraction of RCA (FRCA), essentially composed of mortar and hardened cement paste, possesses a large water demand which makes it harder to recycle into concrete and mortar compared to coarser RCA [11-15].

Lots of studies showed that the properties of concrete decreased as the replacement percentage of FRCA increased [16-18]. For a given replacement percentage, the saturation state of recycled 
aggregate also influences the properties of concrete [19-21]. Poon et al. [19] showed that oven dried coarse recycled concrete aggregates (CRCA) led to a higher initial slump and a quicker slump loss comparing with saturated surface dried CRCA. Moreover oven dried CRCA led to concrete that exhibited higher compressive strength than that with saturated surface dried CRCA. However, the influence of saturation state of recycled sand on the properties of mortars has not been systematically studied.

Like concrete, mortar manufactured with FRCA generally present a lower strength and as a consequence a lesser durability than similar mortar composed of natural sand [22-24]. Generally, compressive strength of mortar decreases as the content of FRCA increases. A few authors mentioned that the use of FRCA does not jeopardize the mechanical properties of mortar up to a replacement of $30 \%[25,26]$. But for other authors the use of FRCA is not good for the properties of mortar due to the high water absorption and adherent cement paste content [27-30]. However, the influence of different granular classes of the recycled sand on the properties of mortars has not been systematically studied.

The objectives of this work were twofold: the influence of saturation state of recycled sand on the properties of mortars has been firstly explored; then the influence of either replacement percentage or replacement fraction of natural sand by recycled sand on the properties of mortars has been evaluated. The properties of mortars including fresh properties (slump), mechanical properties (compressive strength and flexural strength), and ITZ microstructure have been analyzed.

Table 1

Mineralogical composition of cement determined by XRD-Rietveld.

\begin{tabular}{llllllll}
\hline & $\mathrm{C}_{3} \mathrm{~S}$ & $\mathrm{C}_{2} \mathrm{~S}$ & $\mathrm{C}_{3} \mathrm{~A}$ & $\mathrm{C}_{4} \mathrm{AF}$ & Anhydrite & Calcite & Periclase \\
\hline $\begin{array}{c}\text { CEM I 52.5 } \\
\text { superblanc (\%) }\end{array}$ & 73.90 & 21.87 & 1.46 & - & 0.52 & 1.53 & 0.72 \\
\hline
\end{tabular}

\section{Materials and methods}

\subsection{Materials}

Materials used in this study are as follows.

\subsubsection{Cement}

The cement used in mortars was a white Ordinary Portland Cement (CEM I 52.5 "superblanc") provided by Lafarge company whose mineralogical composition is shown in Table 1. White cement has been chosen in order to differentiate more easily the new cement paste from the FRCA

\subsubsection{Natural sand and FRCA}

A calcareous natural sand was used for the manufacture of mortars. It was provided by the Holcim Company and was sourced from the quarry of Tournai. The water absorption of this sand was $1.05 \%$ according to the standard EN 10976 [31], and its density was $2.66 \mathrm{~g} / \mathrm{cm}^{3}$ measured by helium pycnometer (Micromeritics AccuPyc 1330).

The recycled sand used was provided by the Colas Company and has been produced in the recycling platform of Amiens (France). The density of this recycled sand was $2.54 \mathrm{~g} / \mathrm{cm}^{3}$ measured by helium pycnometer. It was divided into four granular fractions $(0 / 0.63,0.63 / 1.25,1.25 / 2.5,2.5 / 5 \mathrm{~mm})$ that were remixed together with specific amounts to get a similar granular distribution than natural sand The particle size distributions of natural and recycled sands (before and after recomposition) are shown Fig. 1. The water absorption of remixed recycled sand was determined according to the method developed by Zhao et al. [32]. The soluble fraction in salicylic acid (SFSA) of each granular fraction of recycled sand was first determined. SFSA is proportional to the cement paste content in RCA. The water absorption (WA) of the three coarser granular fractions was also measured by the method EN 1097-6. As the water absorption of the different granular fractions varies linearly with the cement paste content [32], the water absorption of fraction $0 / 0.63 \mathrm{~mm}$ can be extrapolated from the relationship between SFSA and water absorption values of the three coarser fractions (Table 2). Knowing the particle size distribution of remixed FRCA, the total water absorption coefficient of remixed FRCA (fraction $0 / 5 \mathrm{~mm}$ ) was calculated as $7.54 \%$ (Table 2). Two saturation states of FRCA (Dried RCA and Saturated RCA) were used in this study. Dried RCA were obtained by heating the aggregates at $105^{\circ} \mathrm{C}$ during $24 \mathrm{~h}$. For the saturated RCA the sample was presaturated $24 \mathrm{~h}$ before the fabrication of mortars.

\subsubsection{Compositions of mortars}

Three series of mortars were manufactured in the laboratory. Series I was used to study the influence of saturation state of FRCA on the properties of mortars.

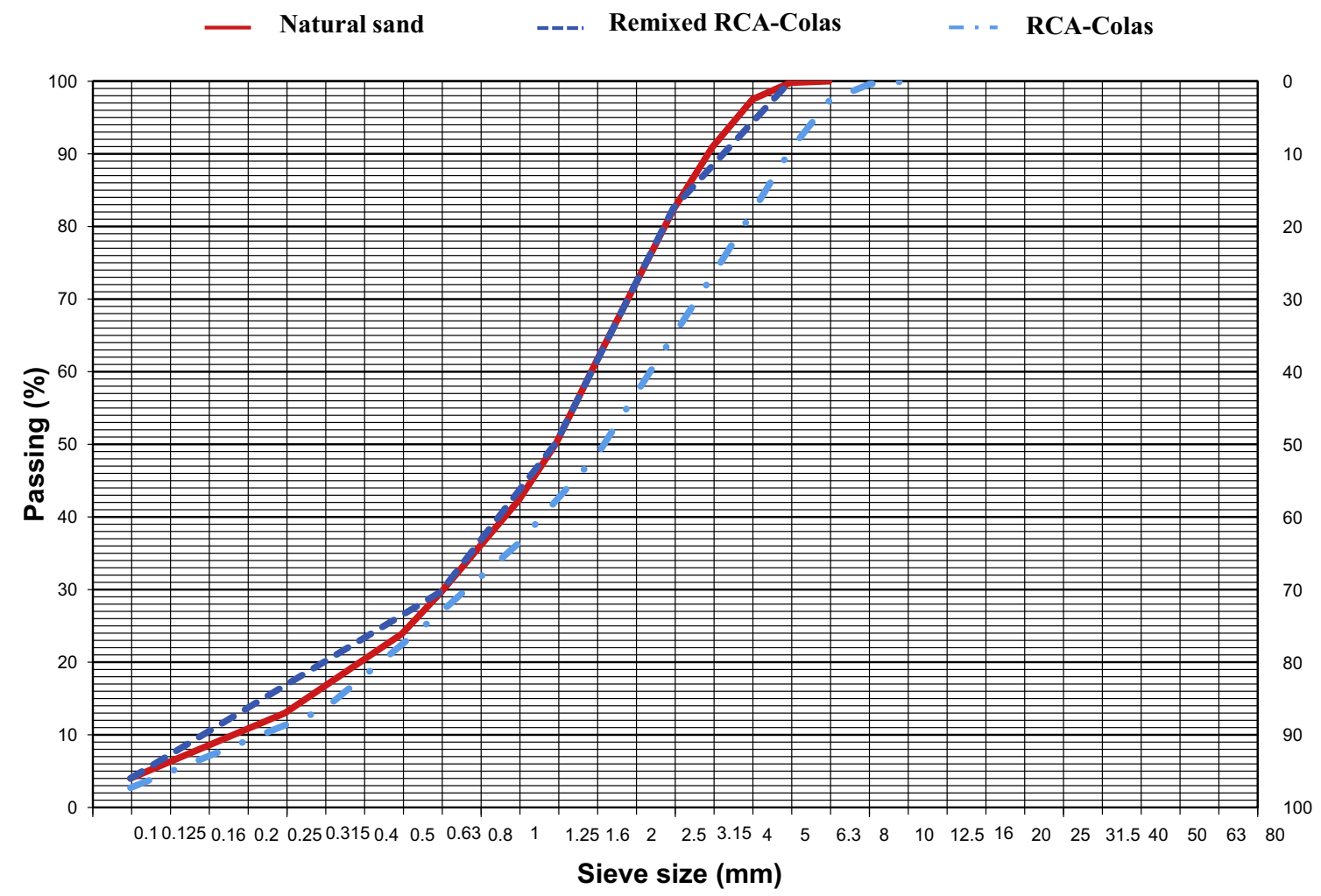

Fig. 1. Particle size distributions of natural and recycled sands used in mortars. 
Table 2

Calculation of water absorption of RCA $0 / 5 \mathrm{~mm}(\%)$.

\begin{tabular}{|c|c|c|c|c|}
\hline & $0 / 0.63 \mathrm{~mm}$ & $0.63 / 1.25 \mathrm{~mm}$ & $1.25 / 2.5 \mathrm{~mm}$ & $2.5 / 5 \mathrm{~mm}$ \\
\hline Percentage of particle distribution & 29.6 & 20.6 & 32.1 & 17.5 \\
\hline SFSA $(\%)$ & 13.46 & 12.45 & 10.22 & 9 \\
\hline WA (EN1097-6) & - & 8.01 & 7.03 & 6.43 \\
\hline Extrapolated WA according to [32] & 8.48 & - & - & - \\
\hline Calculated WA of RCA $0 / 5 \mathrm{~mm}$ & 7.54 & & & \\
\hline
\end{tabular}

Table 3

Compositions of mortars Series I.

\begin{tabular}{lllll}
\hline & Cement $(\mathrm{g})$ & $\begin{array}{l}\text { Recycled } \\
\text { sand }(\mathrm{g})\end{array}$ & $\begin{array}{l}\text { Efficient } \\
\text { water }(\mathrm{g})\end{array}$ & $\begin{array}{l}\text { Absorbed } \\
\text { water }(\mathrm{g})\end{array}$ \\
\hline CM-0.5-S & 450 & $1350^{*}$ & 225 & 14.18 \\
CM-0.5-D & 450 & 1350 & 225 & 14.18 \\
RM-0.5-S & 450 & $1291.1^{*}$ & 225 & 97.35 \\
RM-0.5-D & 450 & 1291.1 & 225 & 97.35 \\
RM-0.55-S & 450 & $1291.1^{*}$ & 247.5 & 97.35 \\
RM-0.55-D & 450 & 1291.1 & 247.5 & 97.35 \\
RM-0.6-S & 450 & $1291.1^{*}$ & 270 & 97.35 \\
RM-0.6-D & 450 & 1291.1 & 270 & 97.35 \\
\hline
\end{tabular}

Remark: *Presaturated $24 \mathrm{~h}$ before mixing.

Series II was used to study the influence of proportions of recycled sand on the mechanical properties of mortars. Series III was made to study the influence of each granular fraction of recycled sand on the properties of mortars. In all the studied series, natural calcareous sand was partially or totally replaced by the same volume of remixed recycled sand.

Table 3 shows the compositions of series I mortars manufactured with natural calcareous and recycled sands. These mortars are noted RM-W/C-S or RM-W/C-D in the following, RM referring to a recycled mortar (CM for calcareous mortar), $W / C$ referring to the efficient water to cement mass ratio, and $S$ or $D$ referring to the saturation state of aggregates ( $S$ refers to saturated sand whereas $D$ corresponds to dried sand but absorbed water being added in the mixer). Three $W / C$ ratios of $0.5,0.55$, and 0.6 were studied for this series.

Table 4 shows the compositions of series II mortars with $W / C=0.5$ manufactured with different proportions of recycled sand. These mortars are noted RM$W / C$-Proportion in the following, $W / C$ referring to the efficient water to cement ratio, and Proportion referring to the volume replacement of recycled sand. For example, RM-0.5-10 refers to the mortar manufactured with $W / C$ of 0.5 , and $10 \%$ of natural sand being replaced by the same volume of recycled sand. Mortars with $W / C$ ratio of 0.6 were also studied just changing the efficient water quantity while other quantities of materials used being the same as the mortar with $W / C$ ratio of 0.5 . Both recycled sand and natural sand in series II were presaturated $24 \mathrm{~h}$ before manufacture.

Table 5 shows the compositions of mortars series III with $W / C=0.5$ manufactured with replacing each granular fraction of natural sand with the corresponding granular fraction of recycled sand. These mortars are noted RM-W/C-Fraction in the following, $W / C$ referring to the efficient water to cement ratio, and Fraction referring to the replacement granular fraction of recycled sand. For example, RM-0.5-0/0.63 refers to the mortar manufactured with $W / C$ of 0.5 , the fraction $0 / 0.63 \mathrm{~mm}$ of natural sand being replaced with the same volume of the fraction $0 / 0.63 \mathrm{~mm}$ of recycled sand. As a consequence, the other fractions from $0.63 \mathrm{up}$ to $5 \mathrm{~mm}$ correspond to natural sand. Mortars with $W / C$ ratio of 0.6 were also studied just changing the efficient water quantity and thus leaving the other quantities of materials unchanged compared to mortars made with $W / C$ ratio of 0.5 . All the sands in series III were presaturated $24 \mathrm{~h}$ before manufacture.

\subsection{Experimental methods}

2.2.1. Mixing procedure for the manufacture of mortars

For mortars manufactured with saturated aggregates, the natural and recycled sands were kept in sealed bags $24 \mathrm{~h}$ before fabrication with part of the mixing water
Table 5

Compositions of mortars series III with $W / C=0.5$.

\begin{tabular}{llllll}
\hline & Control & RM-0.5-0/ & RM-0.5- & RM-0.5- & RM-0.5- \\
& Mortar & 0.63 & $0.63 / 1.25$ & $1.25 / 2.5$ & $2.5 / 5$ \\
\hline Sand 0/0.63 $(\mathrm{g})$ & 399.60 & 376.32 & 399.60 & 399.60 & 399.60 \\
Sand 0.63/1.25 $(\mathrm{g})$ & 278.10 & 278.10 & 263.99 & 278.10 & 278.10 \\
Sand 1.25/2.5 $(\mathrm{g})$ & 433.35 & 433.35 & 433.35 & 413.47 & 433.35 \\
Sand 2.5/5 $(\mathrm{g})$ & 238.95 & 238.95 & 238.95 & 238.95 & 229.52 \\
Total sand $(\mathrm{g})$ & 1350.00 & 1326.72 & 1335.89 & 1330.12 & 1340.57 \\
Cement $(\mathrm{g})$ & 450 & 450 & 450 & 450 & 450 \\
Efficient water $(\mathrm{g})$ & 225 & 225 & 225 & 225 & 225 \\
Absorbed water $(\mathrm{g})$ & 14.18 & 41.89 & 32.40 & 38.69 & 26.42 \\
\hline
\end{tabular}

Remark: the value in italic is the quantity of recycled sand while the others correspond to natural sand.

(a water quantity that is much larger that the absorbed water). The remaining water was added at the fabrication (the water quantity added into the bowl corresponds to the total water quantity minus the water used for the presaturation of the sand). For mortars manufactured with dried FRCA, the quantities of efficient water and absorbed water were added at the fabrication leading to an increase of the initial efficient $W / C$ ratio. The precise mixing procedure was followed according to the standard EN 196-1 [33].

\subsubsection{Slump test}

After mixing, the slump of mortar was measured with the mini MBE cone ("Mortiers de Béton Equivalent" that can be translated as "Equivalent Mortars to Concrete" with respect to the surface of solids relative to the fluid that is the cement paste in mortar and the mortar in concrete) [34] which is shown in Fig. 2. When the slump value is measured as a function of time (series I), the specimen is put again into the bowl of the mixer after the slump test and is prevented from evaporation with plastics films during the waiting time. Before the new slump test, the specimen is remixed at high speed for $60 \mathrm{~s}$.

\subsubsection{Mechanical properties}

The preparation of specimens $(40 \mathrm{~mm} \times 40 \mathrm{~mm} \times 160 \mathrm{~mm})$ for mechanical strength tests was followed according to EN 196-1 [33]. The flexural and compressive strengths of hardened mortar were determined in accordance with EN 196-1
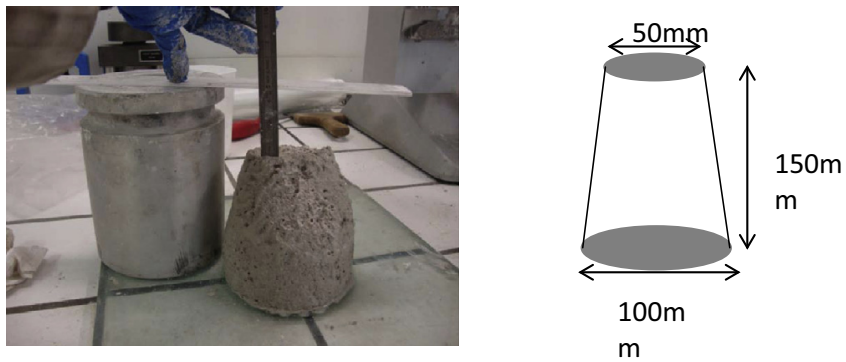

Fig. 2. Mini MBE cone test for measuring slump of mortar.

Table 4

Compositions of mortars series II with $W / C=0.5$.

\begin{tabular}{|c|c|c|c|c|c|c|}
\hline & RM-0.5-0 & RM-0.5-10 & RM-0.5-20 & RM-0.5-30 & RM-0.5-50 & RM-0.5-100 \\
\hline Recycled sand (g) & 0.0 & 129.1 & 258.2 & 387.3 & 645.6 & 1291.1 \\
\hline Natural sand (g) & 1350.0 & 1215.0 & 1080.0 & 944.9 & 675.0 & 0.0 \\
\hline Total Sand (g) & 1350.0 & 1344.1 & 1338.2 & 1332.2 & 1320.6 & 1291.1 \\
\hline Cement (g) & 450 & 450 & 450 & 450 & 450 & 450 \\
\hline Efficient water (g) & 225 & 225 & 225 & 225 & 225 & 225 \\
\hline Absorbed water (g) & 14.18 & 22.5 & 30.81 & 39.13 & 55.77 & 97.35 \\
\hline
\end{tabular}




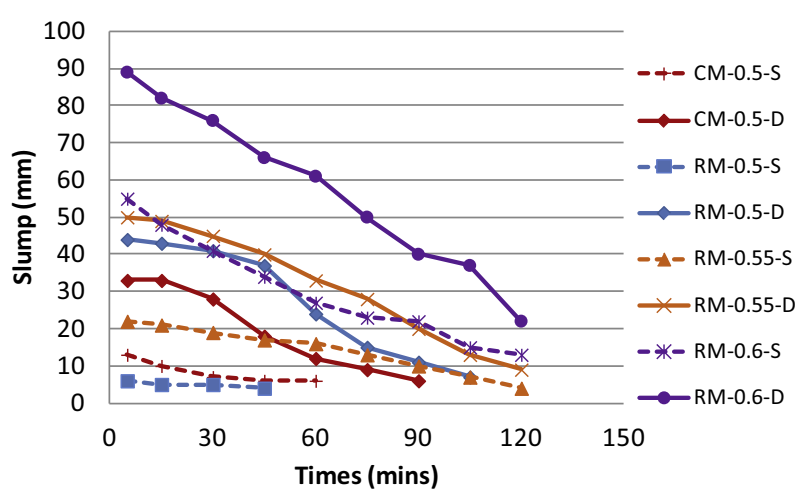

Fig. 3. Changes of slump as a function of time for mortar series I.

Table 6

Coefficients of the linear relationships between slump and time $(y=a x+b)$.

\begin{tabular}{llrl}
\hline & $a$ & $b$ & $R^{2}$ \\
\hline CM-0.5-S & -0.13 & 12.34 & 0.88 \\
CM-0.5-D & -0.35 & 36.02 & 0.97 \\
RM-0.5-S & -0.01 & 6.00 & 1.00 \\
RM-0.5-D & -0.37 & 39.02 & 0.99 \\
RM-0.55-S & -0.15 & 23.71 & 0.98 \\
RM-0.55-D & -0.38 & 54.94 & 0.99 \\
RM-0.6-S & -0.36 & 52.54 & 0.96 \\
RM-0.6-D & -0.56 & 91.90 & 0.99 \\
\hline
\end{tabular}

[33]. These two mechanical tests were carried out with an INSTRON 5500R 4206006 (loading capacity $1500 \mathrm{kN}$ ) after being cured 28 days in water.

\subsubsection{ITZ characterization}

Scanning Electron Microscope (SEM) with Energy Dispersive X-ray Spectroscopy (EDS) analysis was carried out with HITACHI S-4300SE/N. Preliminary observations on flat polished sections showed that it was difficult to distinguish ITZ in mortars containing recycled sand. Therefore a simpler model system of ITZ was studied. Model RCA (particle size $2.5 / 5 \mathrm{~mm}$ ) was manufactured by crushing a sample of old white cement paste made with a water to cement ratio of 0.6 and cured 90 days in water at room temperature. A large $W / C$ ratio was used in order to have a model RCA with a high porosity and water absorption capacity. Dried or saturated states were studied for the model RCA (saturated was achieved after $24 \mathrm{~h}$ of immersion). The dried or the saturated model RCA was placed in the center of small cylinder mold $(2 \mathrm{~cm} \times 2 \mathrm{~cm} \times 1 \mathrm{~cm})$ and embedded with a gray cement paste (cement Lafarge Durabat X-Trem CEM I 52.5) having a $W / C$ ratio of 0.5 . The curing conditions were the same as for mortars. After 28 days curing in water, the samples were dried at $105^{\circ} \mathrm{C}$ and successively polished until the exposure of the model RCA easily recognized thanks to its white color. Here CPS refers to cement paste with saturated model RCA while CPD corresponds to the cement paste containing the dried model RCA.

The cement paste in model RCA does not contain ferrite phases, while the new cement paste made from the gray cement, contains ferrite phases. The presence or the absence of iron when chemical mappings are made by EDS under SEM is thus a good indicator to differentiate the cement paste belonging to model RCA from the one corresponding to the new cement paste. As a consequence ITZ may be more precisely identified by SEM observations coupled with EDS mapping.

\section{Results}

\subsection{Influence of saturation state}

\subsubsection{Slump tests}

Fig. 3 shows the variation of slump as a function of time for mortars series $I$. For the three studied $W / C$ ratios, the slump of mortars made with dried aggregates is always higher than the slump obtained for mortars having saturated aggregates. It is important here to recall that, for a given $W / C$ ratio, the compositions of mortars made with dried or saturated aggregates are exactly the same (see Table 3). However, in the case of saturated sand, absorbed water is initially present inside the porosity of sand particles at the beginning of mixing $\left(T_{0}\right)$ and thus trapped in the sand particles. On the contrary, in the case of dried sand, the theoretical amount of absorbed water is initially incorporated into the mixer at the beginning of mixing in addition to the water required to get the desired $W / C$ ratio. Thus, the additional water corresponding to the theoretical amount of absorbed water induces a temporary increase of the initial efficient $W / C$ ratio and volume of paste, leading to a better workability before its absorption into FRCA as water is not immediately adsorbed into the cement paste of the recycled sand at the initial time $\left(T_{0}\right)$. As a consequence, a higher slump value is obtained when compared to mortar made with saturated aggregates. For example, in the mortar RM-0.5- $D$ at the beginning, the efficient $W / C$ is 0.72 , while it is 0.5 for RM-0.5-S. Moreover, the volume proportion of paste in RM-0.5$D$ is $44 \%$ while it is only $38 \%$ for RM- $0.5-S$. Therefore, the initial slump of RM-0.5-D is much higher than RM-0.5-S.

The rate of slump loss of RM-D is quicker than that of RM-S, which is expected to be a consequence of the absorption of free water in the cement paste of the recycled sand but also to the higher initial slump value. For example, the slope of RM-0.5-S is almost zero due to the very small initial slump value while the slope of slump loss for RM-0.5-S is $0.37 \mathrm{~mm} / \mathrm{min}$ with an initial slump value of $44 \mathrm{~mm}$, as shown in Table 6 . However, whatever the $W / C$ ratio used, the slump value of mortars manufactured with dried aggregates is always larger than that of mortars manufactured with saturated aggregates. This result suggests that the absorption of water by dried aggregates in the mortar is lower and/or slowly than the absorption determined with standard procedures. It could be due first to the kinetics of absorption. The time of immersion of aggregates into mixing water before placing is much smaller than the $24 \mathrm{~h}$ immersion used in the standards. But it could also be partly due to a lesser water absorption capacity of aggregates when

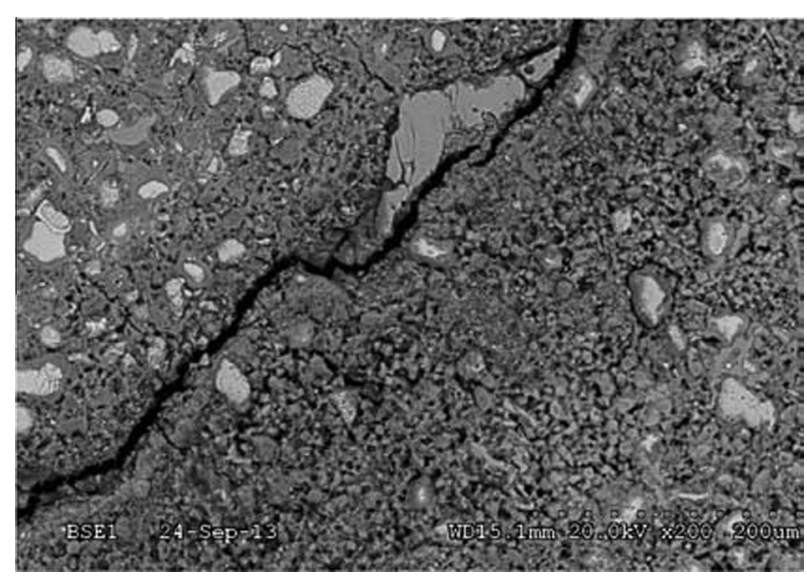

Fig. 4. SEM image (backscattered electrons) of ITZ of CPS

Table 7

Properties of mortars series I.

\begin{tabular}{|c|c|c|c|c|c|c|c|c|}
\hline & CM-0.50-S & CM-0.50-D & RM-0.50-S & RM-0.50-D & RM-0.55-S & RM-0.55-D & RM-0.60-S & RM-0.6-D \\
\hline $\begin{array}{l}\text { Fresh density } \\
\qquad\left(\mathrm{g} / \mathrm{cm}^{3}\right)\end{array}$ & 2.40 & 2.36 & 2.15 & 2.14 & 2.16 & 2.13 & 2.16 & 2.12 \\
\hline 28 days saturated density $\left(\mathrm{g} / \mathrm{cm}^{3}\right)$ & 2.40 & 2.38 & 2.15 & 2.15 & 2.18 & 2.15 & 2.17 & 2.13 \\
\hline Flexural strength (MPa) & 11.97 & 12.15 & 8.76 & 8.78 & 8.10 & 8.15 & 7.72 & 7.80 \\
\hline Compressive strength (MPa) & 66.75 & 72.00 & 45.22 & 49.84 & 43.01 & 45.34 & 41.96 & 43.76 \\
\hline
\end{tabular}




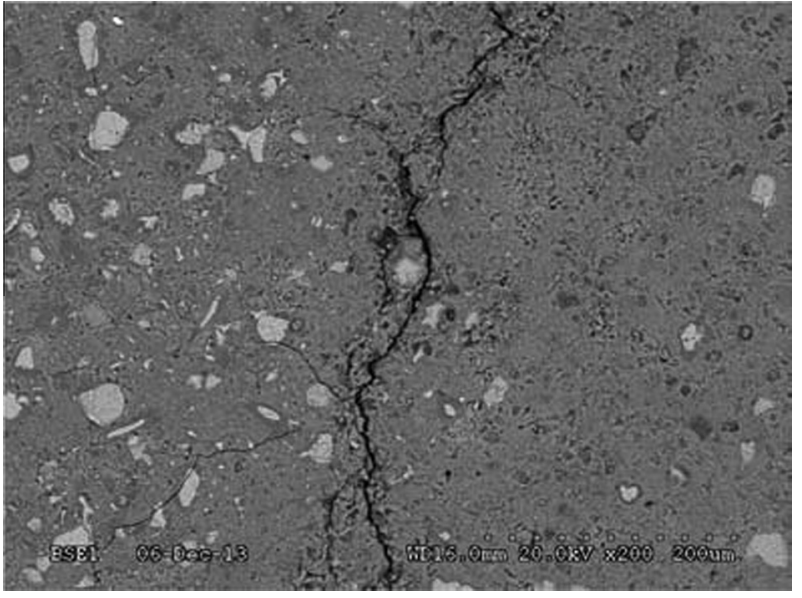

Fig. 5. SEM image (backscattered electrons) of ITZ of CPD.

they are immersed into the cement paste in which water molecules interact with the large specific surface area of cement grains but also with ions released by cement hydration. Moreover, some surface porosity of RCA could be filled with small cement particles, reducing the absorption capacity of RCA.

\subsubsection{Mechanical properties of mortars}

Table 7 shows the mechanical properties of mortars of series I. As it can be seen, with the same volume of aggregates, the flexural
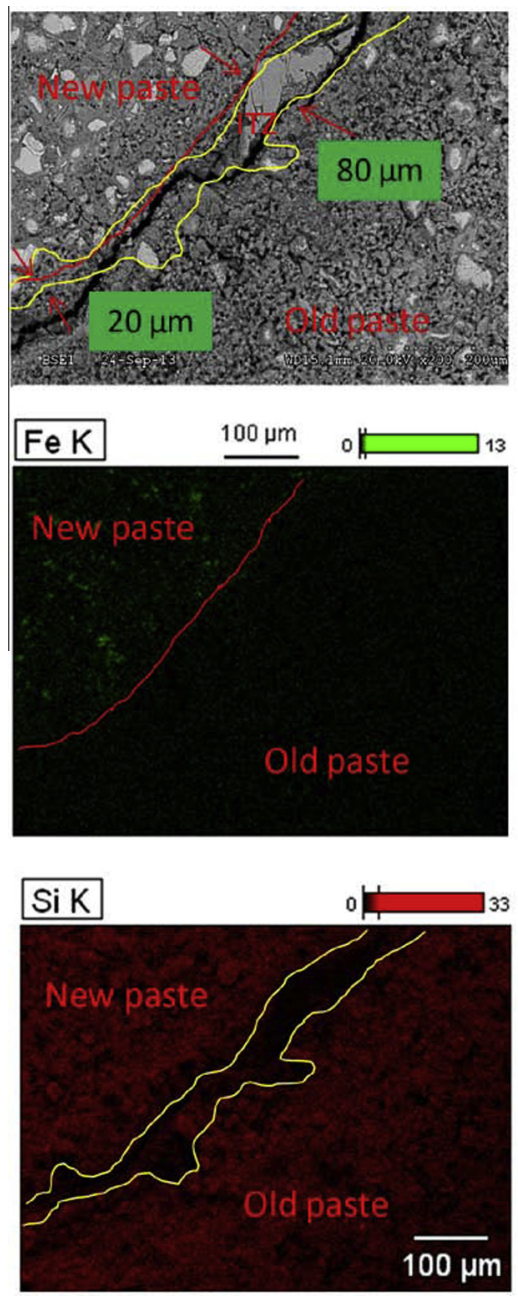

and compressive strengths of mortars are lower than that of the reference mortar made with calcareous sand. This is observed whatever the saturation state of FRCA. For example, the compressive strength of RM-0.5-S decreases 32.3\% comparing with CM-0.5$S$, while the compressive strength of RM-0.5-D decreases $30.8 \%$ comparing with CM-0.5-D. These lower mechanical strengths are certainly caused by the poorer properties of recycled sand in comparison to calcareous sand used; the presence of adherent cement paste leads to higher porosity and water absorption comparing with the calcareous sand.

Flexural strengths of mortars with the saturated and dried aggregates are almost the same both for the mortar with recycled sand and reference mortar. On the contrary, the compressive strength of mortars (either with natural or recycled sand) with dried aggregates is always larger than with saturated aggregates; increase by $7.9 \%$ for calcareous sand compared to an increase by $10.2 \%, 5.4 \%$, and $4.3 \%$ with $W / C$ ratios $0.5,0.55$, and 0.6 , respectively for FRCA. Moreover this increase is observed despite the larger initial $W / C$ of these mortars and especially those made with dried FRCA. These results are in accordance with the results obtained by Poon et al. [19] and Nguyen [21].

\subsubsection{ITZ properties}

Figs. 4 and 5 show the SEM results (backscattered electrons on flat polished section) obtained on simpler model system of ITZ made with saturated or dried model RCA named respectively CPS and CPD. Additionally Fig. 6 shows the results of the mapping by
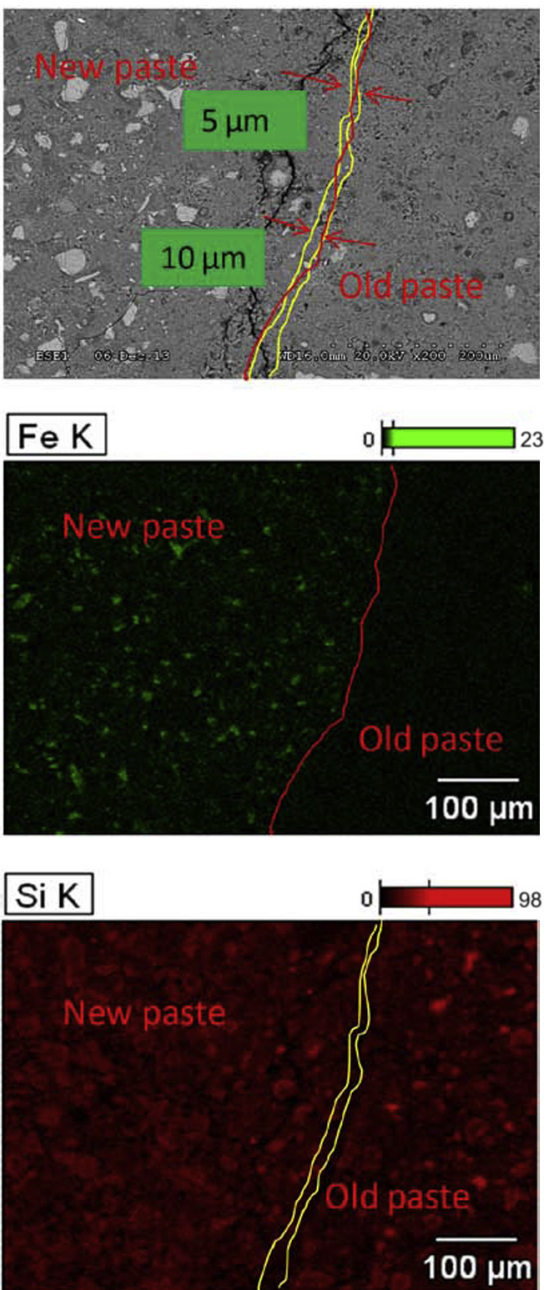

Fig. 6. Elemental analysis with EDS results of ITZ of CPS (left) and CPD (right). 
EDS of iron and silicon. From the elemental distribution of iron, the cement paste corresponding to the model RCA aggregate is identified by the area where no Fe element is detected contrarily to the new paste. Indeed during hydration, iron ions tend to precipitate close to the initial position on or nearby $\mathrm{C}_{4} \mathrm{AF}$ grains as they do not diffuse far way from anhydrous phases due to the very low solubility of iron containing hydrates. Thus iron mapping enables us to determine the localization of ITZ (red curve on Fig. 6) but it cannot be used to estimate its thickness. On the other hand, silicate ions also do not diffuse far away from cement grains leading generally to ITZ poorer in silicon while it is richer in calcium as portlandite is abundant in ITZ. The area with a lower silicon concentration and close to the zone containing no iron therefore corresponds to the ITZ which is initially filled with water. This area is well defined for the model aggregate that was saturated leading to ITZ thickness between 20 and $80 \mu \mathrm{m}$ (two yellow curves on Fig. 6). On the other hand, ITZ corresponding to the dried model aggregate appears to be finer with a thickness ranging from 5 to $10 \mu \mathrm{m}$ (two yellow curves on Fig. 6). The ITZ is therefore influenced by the saturation states of the cement paste contained in FRCA. The following explanation can therefore be proposed for the ITZ microstructure of mortars depending on the saturation state of FRCA (Fig. 7). With saturated FRCA, water goes from the surface of the cement paste of FRCA to the new paste, increasing locally the $W / C$ ratio at the surface of aggregate and thus leading to a large ITZ. On the contrary, for the dried FRCA, water moves from the bulk into the dried aggregate even if this process is not instantaneous as demonstrated by the slump loss. The cement grains are dragged together with water, reducing locally the $\left(W_{\text {eff }} / C\right)$ at the surface of aggregate and leading new hydrates to precipitate at the surface or near the inside of cement paste of FRCA. This leads to an improved ITZ in mortars manufactured with dried RCA in comparison to those manufactured with saturated ones. Compressive strengths obtained for mortars manufactured with dried aggregates are all larger than those obtained for saturated aggregates. This result shows that the improvement of mechanical properties of the ITZ in mortars containing dried aggregates is able to compensate the decrease in mechanical properties of the bulk paste of these mortars due to the larger initial $\left(W_{\text {eff }} / C\right)$. These results are obtained in a simple system; they also need to be verified with a statistical approach for several ITZ and for other materials. Nevertheless the micro-cracks observed in both samples and probably induced by the preparation of samples (heating at $105{ }^{\circ} \mathrm{C}$ and then polishing) confirms that ITZ in the sample made with saturated model RCA has some weak mechanical properties as the micro-crack passes through it (Fig. 6). On the other hand, the micro-cracks of the sample made with the dried model RCA passes either in the cement paste or in the ITZ leading to consider close mechanical properties (Fig. 6).

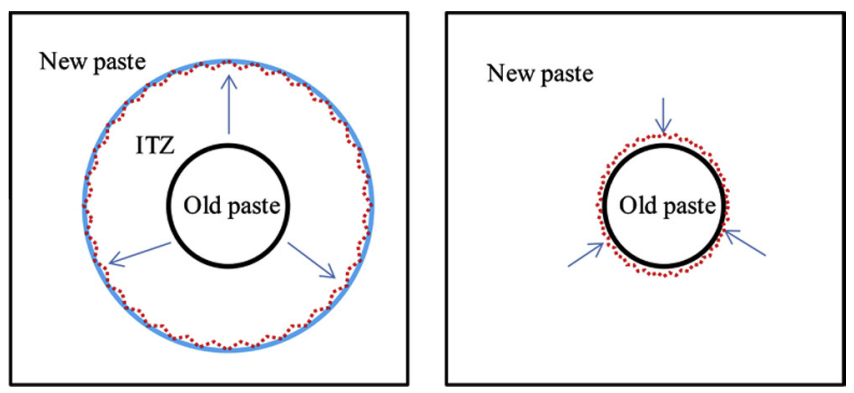

Fig. 7. Models of ITZ for CPS (left) and CPD (right), here red point refers to the hydrates, blue circle refers to the front between new paste and ITZ, black circle refers to the front between old paste and ITZ, arrow refers to moving direction of water. (For interpretation of the references to color in this figure legend, the reader is referred to the web version of this article.)
Table 8

Properties of mortars series II.

\begin{tabular}{|c|c|c|c|c|c|c|}
\hline$W / C=0.5$ & $\begin{array}{l}\mathrm{RM}- \\
0.5-0\end{array}$ & $\begin{array}{l}\text { RM- } \\
0.5-10\end{array}$ & $\begin{array}{l}\text { RM- } \\
0.5-20\end{array}$ & $\begin{array}{l}\text { RM- } \\
0.5-30\end{array}$ & $\begin{array}{l}\text { RM- } \\
0.5-50\end{array}$ & $\begin{array}{l}\text { RM-0.5- } \\
100\end{array}$ \\
\hline Slump (mm) & 27 & 17 & 19 & 29 & 8 & 5 \\
\hline $\begin{array}{l}\text { Fresh density } \\
\qquad\left(\mathrm{g} / \mathrm{cm}^{3}\right)\end{array}$ & 2.37 & 2.37 & 2.34 & 2.30 & 2.26 & 2.15 \\
\hline $\begin{array}{l}\text { Flexural strength } \\
\quad(\mathrm{MPa})\end{array}$ & 12.14 & 13.06 & 12.05 & 10.86 & 10.53 & 8.54 \\
\hline $\begin{array}{l}\text { Compressive } \\
\text { strength (MPa) }\end{array}$ & 67.77 & 66.63 & 64.58 & 57.23 & 53.84 & 42.09 \\
\hline$W / C=0.6$ & $\begin{array}{l}\text { RM- } \\
0.6-0\end{array}$ & $\begin{array}{l}\text { RM- } \\
0.6-10\end{array}$ & $\begin{array}{l}\text { RM- } \\
0.6-20\end{array}$ & $\begin{array}{l}\text { RM- } \\
0.6-30\end{array}$ & $\begin{array}{l}\text { RM- } \\
0.6-50\end{array}$ & $\begin{array}{l}\text { RM-0.6- } \\
100\end{array}$ \\
\hline Slump (mm) & 105 & 93 & 80 & 76 & 70 & 55 \\
\hline $\begin{array}{l}\text { Fresh density } \\
\qquad\left(\mathrm{g} / \mathrm{cm}^{3}\right)\end{array}$ & 2.31 & 2.27 & 2.27 & 2.26 & 2.20 & 2.15 \\
\hline $\begin{array}{l}\text { Flexural strength } \\
\quad(\mathrm{MPa})\end{array}$ & 10.63 & 10.55 & 10.21 & 10.00 & 9.16 & 8.00 \\
\hline $\begin{array}{l}\text { Compressive } \\
\text { strength (MPa) }\end{array}$ & 55.98 & 51.17 & 49.32 & 47.37 & 46.92 & 39.14 \\
\hline
\end{tabular}

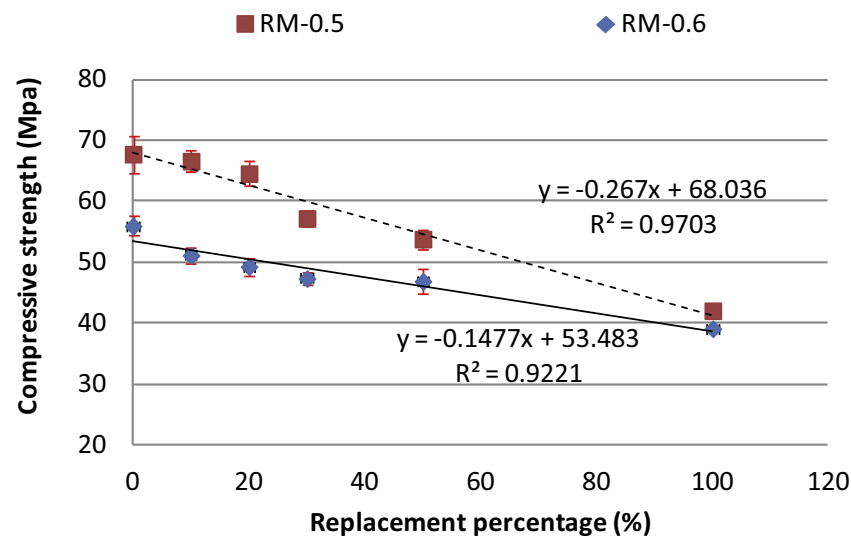

Fig. 8. Compressive strength of mortar vs replacement percentage.

Table 9

Properties of mortars series III.

\begin{tabular}{|c|c|c|c|c|c|}
\hline$W / C=0.5$ & $\begin{array}{l}\text { Control } \\
\text { Mortar }\end{array}$ & $\begin{array}{l}\text { RM-0.5- } \\
0 / 0.63\end{array}$ & $\begin{array}{l}\text { RM-0.5- } \\
0.63 / 1.25\end{array}$ & $\begin{array}{l}\text { RM-0.5- } \\
1.25 / 2.5\end{array}$ & $\begin{array}{l}\text { RM-0.5- } \\
2.5 / 5\end{array}$ \\
\hline Slump (mm) & 20 & 9 & 13 & 12 & 21 \\
\hline $\begin{array}{l}\text { Fresh density } \\
\quad\left(\mathrm{g} / \mathrm{cm}^{3}\right)\end{array}$ & 2.36 & 2.28 & 2.28 & 2.27 & 2.37 \\
\hline $\begin{array}{l}\text { Flexural strength } \\
\qquad(\mathrm{MPa})\end{array}$ & 11.01 & 10.19 & 9.66 & 9.83 & 11.22 \\
\hline $\begin{array}{l}\text { Compressive } \\
\text { strength (MPa) }\end{array}$ & 63.71 & 45.55 & 52.54 & 52.22 & 58.32 \\
\hline$W / C=0.6$ & $\begin{array}{l}\text { Control } \\
\text { Mortar }\end{array}$ & $\begin{array}{l}\text { RM-0.6- } \\
0 / 0.63\end{array}$ & $\begin{array}{l}\text { RM-0.6- } \\
0.63 / 1.25\end{array}$ & $\begin{array}{l}\text { RM-0.6- } \\
1.25 / 2.5\end{array}$ & $\begin{array}{l}\text { RM-0.6- } \\
2.5 / 5\end{array}$ \\
\hline Slump (mm) & 103 & 93 & 83 & 82 & 90 \\
\hline $\begin{array}{l}\text { Fresh density } \\
\qquad\left(\mathrm{g} / \mathrm{cm}^{3}\right)\end{array}$ & 2.30 & 2.21 & 2.29 & 2.25 & 2.25 \\
\hline $\begin{array}{l}\text { Flexural strength } \\
\quad(\mathrm{MPa})\end{array}$ & 9.95 & 9.24 & 9.67 & 9.77 & 10.38 \\
\hline $\begin{array}{l}\text { Compressive } \\
\text { strength (MPa) }\end{array}$ & 53.74 & 44.29 & 50.06 & 50.85 & 52.08 \\
\hline
\end{tabular}

\subsection{Influence of replacement percentage of recycled sand}

Two series of mortars with two different $W / C$ ratios were used to study the influence of recycled sand on the properties of the mortars. Series II is used to study the influence of the proportions of recycled sand on the mechanical properties of mortars. Series III 


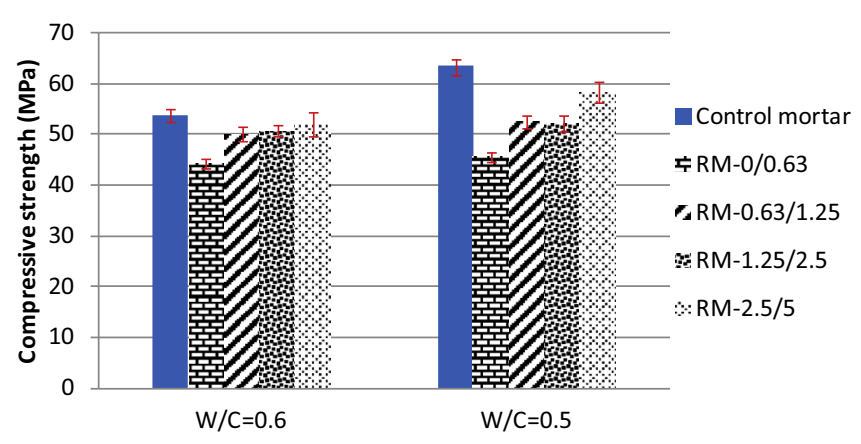

Fig. 9. Compressive strength of mortar series III with each fraction replacement.

is used to study the influence of granular fractions of recycled sand on the properties of mortars.

Table 8 shows the properties of mortars corresponding to series II. As can be seen, for both water to cement ratios, the fresh density decreases as the percentage of sand replacement increases, which is due to the lower density of recycled sand. The compressive strength of mortars decreases as the replacement of recycled sand increases.

Fig. 8 shows the compressive strength of mortar also of series II with $W / C=0.5$ and 0.6 . We can first observe that the strength of mortars varies linearly with the replacement ratio of calcareous sand by recycled sand for both water to cement ratios, which confirms results obtained by Dapena et al. [24]. The slope of the decrease of the compressive strength for mortars made with $W / C=0.5$ is larger than the corresponding mortars realized with $W / C=0.6$.

\subsection{Influence of replacement fraction of recycled sand}

Table 9 shows the properties of mortars belonging to series III. Fig. 9 presents the compressive strength of mortars with each fraction replacement. For both $W / C$ ratios, the compressive strength of mortars containing recycled sand is always lower than the control mortar.

In mortars of series III, two parameters are varying simultaneously: the granular class of recycled sand and the replacement fraction. Indeed, the four granular fractions studied do not represent the same volume of aggregates. In order to study only the effect of granular class of FRCA on the properties of mortars, the
Table 10

Comparison of compressive strengths of mortars series III with series II.

\begin{tabular}{|c|c|c|c|c|}
\hline$W / C=0.5$ & $\begin{array}{l}\text { RM-0.5-0/ } \\
0.63\end{array}$ & $\begin{array}{l}\text { RM-0.5-0.63/ } \\
1.25\end{array}$ & $\begin{array}{l}\text { RM-0.5- } \\
1.25 / 2.5\end{array}$ & $\begin{array}{l}\text { RM-0.5- } \\
2.5 / 5\end{array}$ \\
\hline $\begin{array}{l}\text { Recycled sand by } \\
\text { volume (\%) }\end{array}$ & 29.31 & 20.50 & 32.08 & 17.79 \\
\hline $\begin{array}{l}\text { Relative strength of } \\
\text { series III }\end{array}$ & 0.72 & 0.82 & 0.82 & 0.91 \\
\hline $\begin{array}{l}\text { Calculated relative } \\
\text { strength }\end{array}$ & 0.89 & 0.92 & 0.88 & 0.93 \\
\hline Difference value & -0.17 & -0.10 & -0.06 & -0.02 \\
\hline$W / C=0.6$ & $\begin{array}{l}\text { RM-0.6-0/ } \\
0.63\end{array}$ & $\begin{array}{l}\text { RM-0.6-0.63/ } \\
1.25\end{array}$ & $\begin{array}{l}\text { RM-0.6- } \\
1.25 / 2.5\end{array}$ & $\begin{array}{l}\text { RM-0.6- } \\
2.5 / 5\end{array}$ \\
\hline $\begin{array}{l}\text { Recycled sand by } \\
\text { volume (\%) }\end{array}$ & 29.31 & 20.50 & 32.08 & 17.79 \\
\hline $\begin{array}{l}\text { Relative strength of } \\
\text { series III }\end{array}$ & 0.82 & 0.93 & 0.95 & 0.97 \\
\hline $\begin{array}{l}\text { Calculated relative } \\
\text { strength }\end{array}$ & 0.88 & 0.90 & 0.87 & 0.91 \\
\hline Difference value & -0.06 & 0.03 & 0.07 & 0.06 \\
\hline
\end{tabular}

results of series III have been compared to those obtained with series II. Fig. 10 shows the relationship between the relative strength of mortars and replacement proportion of recycled sand obtained from mortars of series II. The relative compressive strengths of series III are compared with series II on Fig. 10 and in Table 10. The volume fraction of recycled sand in mortars of series III has been calculated. The relative strength is the compressive strength of mortar reported to that of the control mortar. According to the linear relationship between the relative strength of series II and replacement percentage, a calculated relative strength is obtained. The difference between the relative strength of series III and calculated relative strength from series II gives the impact index of each fraction of recycled sand. As can be seen in Table 10, the difference between series II and III for the smaller fraction $(0 / 0.63 \mathrm{~mm})$ is larger than for the coarser ones (a similar result is obtained for mortars having a $W / C$ of 0.6 ). This means that the finer fraction of RCA (fraction $0 / 0.63 \mathrm{~mm}$ ) has a greater detrimental influence than the larger fractions. It is partly due to the higher cement paste content, higher water absorption and lower mechanical properties of the finer fraction of RCA. Therefore, the finer fractions of RCA have the worse influence on the properties of mortars as already known. However the reported method enables us to classify relatively the different fractions but also the different kinds of RCA.

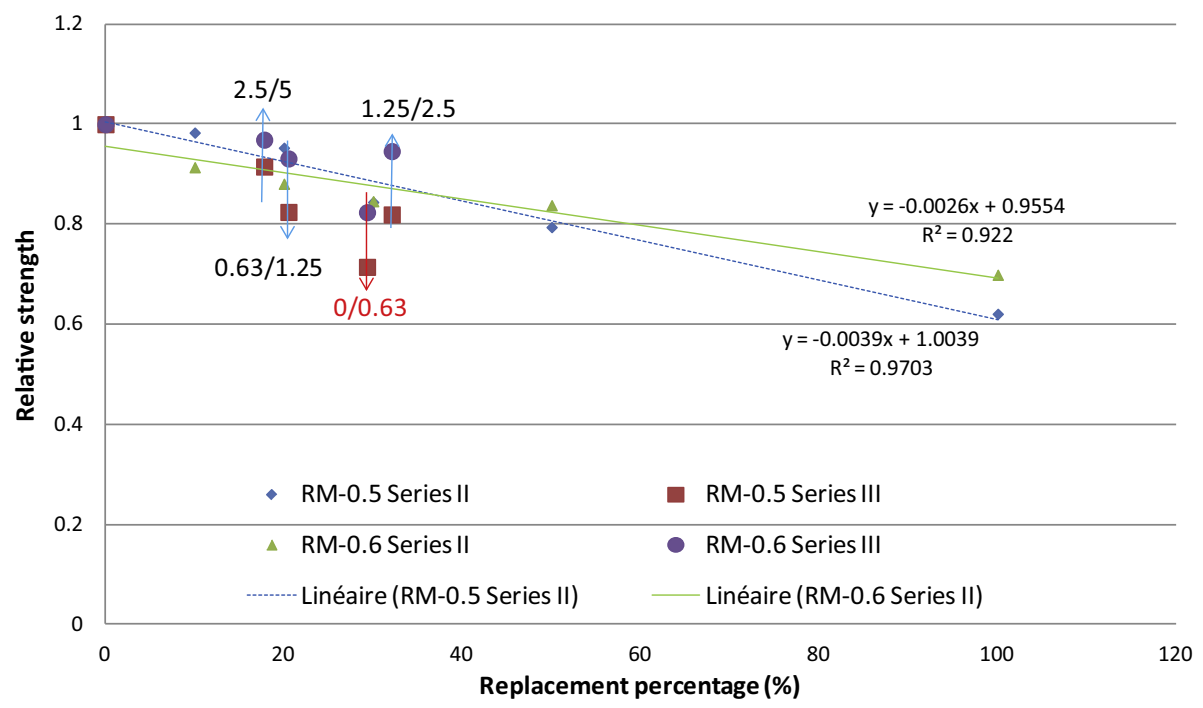

Fig. 10. Relationship between relative compressive strength of mortars and replacement percentage. 


\section{Conclusions}

The properties of mortars containing FRCA including the fresh properties, mechanical properties, and ITZ microstructure have been studied. Thanks to the use of three series of different compositions of mortars, the main conclusions obtained are as follows:

(1) The slump of mortars made with dried recycled sand is higher than that of similar mortars made with saturated recycled sand. This is due both to higher initial free water and paste volume in the mortars manufactured with dried recycled sand. However the rate of slump loss is quicker when using dried recycled sand. This could be partly due to the higher initial slump value, and also due to the decrease of free water by the absorption of recycled sand. However, whatever the $W / C$ ratio used, the slump value of mortars manufactured with dried FRCA is always larger than that of mortars manufactured with saturated aggregates. This result suggests that the absorption of water by dried FRCA in the mortar is lower than the absorption determined with standard procedures. It could be due first to the kinetics of absorption but also to a lesser water absorption capacity of the cement paste contained in FRCA when they are immersed into the cement paste.

(2) The mortars made with dried FRCA have better compressive strengths than the ones with saturated aggregates for the three different $W / C$ ratios studied, despite the larger initial efficient $W / C$ ratio in mortars containing dried aggregates. SEM observations of a simpler model system of ITZ demonstrate that the ITZ between the cement paste and saturated FRCA is larger than with dried FRCA. The thickness of ITZ and thus its properties are improved by the absorption of water by the cement paste contained in FRCA.

(3) With replacing the natural sand with recycled sand, the fresh density of mortar decreases which is due to the lower density of recycled sand. The compressive strength of mortar containing FRCA decreases as the content of FRCA increases. The relationship between the compressive strength and replacement ratio is quasi linear.

(4) The compressive strength of mortar in which some sand fractions have been replaced by the corresponding FRCA is lower than the control mortar for both $W / C$ ratios $(W / C=$ $0.5,0.6)$. Moreover, the finer fraction of FRCA (fraction $0 / 0.63 \mathrm{~mm}$ ) has a worse influence which is partly due to its higher cement paste content, higher water absorption and lower mechanical properties.

\section{Acknowledgments}

Authors would like to thank the Lafarge Company for providing us cements and the Holcim Company for supplying us natural aggregates. Authors would also like to thank the Colas Company for supplying RCA. Finally, authors would like to thank the China Scholarship Council (CSC) for its financial support.

\section{References}

[1] Larrañaga ME. Experimental study on microstructure and structural behaviour of recycled aggregate concrete [thesis]. Universitat Politècnica de Catalunya; 2004.
[2] Xiao J, Xie H, Zhang C. Investigation on building waste and reclaim in Wenchuan earthquake disaster area. Resour Conserv Recycl 2012;61:109-17.

[3] Poon C-S, Chan D. The use of recycled aggregate in concrete in Hong Kong. Resour Conserv Recycl 2007;50(3):293-305.

[4] Oikonomou ND. Recycled concrete aggregates. Cem Concr Compos 2005;27(2):315-8.

[5] Topcu IB, Sengel S. Properties of concretes produced with waste concrete aggregate. Cem Concr Res 2004;34(8):1307-12.

[6] Amnon K. Properties of concrete made with recycled aggregate from partially hydrated old concrete. Cem Concr Res 2003;33(5):703-11.

[7] Rao A, Jha KN, Misra S. Use of aggregates from recycled construction and demolition waste in concrete. Resour Conserv Recycl 2007;50(1):71-81.

[8] de Juan MS, Gutiérrez PA. Study on the influence of attached mortar content on the properties of recycled concrete aggregate. Constr Build Mater 2009;23(2):872-7.

[9] Nagataki S, Gokce A, Saeki T, Hisada M. Assessment of recycling process induced damage sensitivity of recycled concrete aggregates. Cem Concr Res 2004;34(6):965-71.

[10] Abbas A, Fathifazl G, Fournier B, Isgor OB, Zavadil R, Razaqpur AG, et al. Quantification of the residual mortar content in recycled concrete aggregates by image analysis. Mater Charact 2009;60(7):716-28.

[11] Hansen TC. Recycled aggregates and recycled aggregate concrete second stateof-the-art report developments 1945-1985. Mater Struct 1986;19(3):201-46.

[12] Hansen TC, Narud H. Strength of recycled concrete made from crushed concrete coarse aggregate. Concr Int 1983;5(1):79-83.

[13] Xiao J, Li J, Zhang C. Mechanical properties of recycled aggregate concrete under uniaxial loading. Cem Concr Res 2005;35(6):1187-94.

[14] Xiao JZ, Li JB, Zhang C. On relationships between the mechanical properties of recycled aggregate concrete: an overview. Mater Struct 2006;39(6):655-64.

[15] Etxeberria M, Vázquez E, Marí A, Barra M. Influence of amount of recycled coarse aggregates and production process on properties of recycled aggregate concrete. Cem Concr Res 2007;37(5):735-42.

[16] Khatib JM. Properties of concrete incorporating fine recycled aggregate. Cem Concr Res 2005;35(4):763-9.

[17] Shi-Cong K, Chi-Sun P. Properties of concrete prepared with crushed fine stone furnace bottom ash and fine recycled aggregate as fine aggregates. Constr Build Mater 2009;23(8):2877-86.

[18] Evangelista L, de Brito J. Mechanical behaviour of concrete made with fine recycled concrete aggregates. Cement Concr Compos 2007;29(5):397-401.

[19] Poon CS, Shui ZH, Lam L, Fok H, Kou SC. Influence of moisture states of natura and recycled aggregates on the slump and compressive strength of concrete. Cem Concr Res 2004;34(1):31-6.

[20] Poon C, Kou S, Lam L. Influence of recycled aggregate on slump and bleeding of fresh concrete. Mater Struct 2007:40(9):981-8.

[21] Nguyen TD. Étude de la zone d'interphase'granulats calcaires poreux-pâte de ciment': Influence des propriétés physico-mécaniques des granulats; Conséquence sur les propriétés mécaniques du mortier [Thèse]. Ecole Nationale Supérieure des Mines de Saint-Etienne; 2013.

[22] Lee C-H, Du J-C, Shen D-H. Evaluation of pre-coated recycled concrete aggregate for hot mix asphalt. Constr Build Mater 2012;28(1):66-71.

[23] Choi YW, Moon DJ, Kim YJ, Lachemi M. Characteristics of mortar and concrete containing fine aggregate manufactured from recycled waste polyethylene terephthalate bottles. Constr Build Mater 2009;23(8):2829-35.

[24] Dapena E, Alaejos P, Lobet A, Pérez D. Effect of recycled sand content on characteristics of mortars and concretes. J Mater Civ Eng 2011;23:414.

[25] Braga M, de Brito J, Veiga R. Incorporation of fine concrete aggregates in mortars. Constr Build Mater 2012;36:960-8.

[26] Vegas I, Azkarate I, Juarrero A, Frías M. Design and performance of masonry mortars made with recycled concrete aggregates. Mater Constr 2009;59.

[27] Corinaldesi V, Giuggiolini M, Moriconi G. Use of rubble from building demolition in mortars. Waste Manage 2002;22(8):893-9.

[28] Corinaldesi V. Mechanical behavior of masonry assemblages manufactured with recycled-aggregate mortars. Cement Concr Compos 2009;31(7):505-10.

[29] Corinaldesi V, Moriconi G. Influence of mineral additions on the performance of 100\% recycled aggregate concrete. Constr Build Mater 2009;23(8):2869-76.

[30] Lee S-T. Influence of recycled fine aggregates on the resistance of mortars to magnesium sulfate attack. Waste Manage 2009;29(8):2385-91.

[31] EN B. 1097-6. Tests for mechanical and physical properties of aggregates - Part 6: Determination of particle density and water absorption; 2000.

[32] Zhao Z, Remond S, Damidot D, Xu W. Influence of hardened cement paste content on the water absorption of fine recycled concrete aggregates. Sustainable Cem Based Mater 2013;2(3-4):186-203.

[33] EN T. 196-1. Methods of testing cement - Part 1: Determination of strength European Committee for Standardization; 2005:26.

[34] Schwartzentruber A, Catherine C. La méthode du mortier de béton équivalent (MBE)-Un nouvel outil d'aide à la formulation des bétons adjuvantés. Mater Struct $2000 ; 33(8): 475-82$ 